OPEN ACCESS

Edited by:

Yaohua Liu,

Shanghai First People's Hospital,

China

Reviewed by:

Maite Verreault,

INSERM U1127 Institut du Cerveau et de la Moelle épinière (ICM), France

Kristin Huntoon,

University of Texas MD Anderson

Cancer Center, United States

*Correspondence:

Mohammad Taher

mohammad_823@yahoo.com

Soudeh Ghafouri-Fard

s.ghafourifard@sbmu.ac.ir

Specialty section:

This article was submitted to

Neuro-Oncology and

Neurosurgical Oncology,

a section of the journal

Frontiers in Oncology

Received: 04 November 2020 Accepted: 22 December 2020

Published: 03 February 2021

Citation:

Rezaei O, Tamizkar KH, Sharifi G, Taheri M and Ghafouri-Fard S (2021)

Emerging Role of Long Non-Coding

RNAs in the Pathobiology

of Glioblastoma.

Front. Oncol. 10:625884

doi: 10.3389/fonc.2020.625884

\section{Emerging Role of Long Non-Coding RNAs in the Pathobiology of Glioblastoma}

\author{
Omidvar Rezaei ${ }^{1}$, Kasra Honarmand Tamizkar ${ }^{2}$, Guive Sharifi ${ }^{1}$, Mohammad Taheri $^{3 *}$ \\ and Soudeh Ghafouri-Fard ${ }^{2 *}$ \\ 1 Skull Base Research Center, Loghman Hakim Hospital, Shahid Beheshti University of Medical Sciences, Tehran, Iran, \\ 2 Department of Medical Genetics, Shahid Beheshti University of Medical Sciences, Tehran, Iran, ${ }^{3}$ Urogenital Stem Cell \\ Research Center, Shahid Beheshti University of Medical Sciences, Tehran, Iran
}

Glioblastoma is the utmost aggressive diffuse kind of glioma which is originated from astrocytes, neural stem cells or progenitors. This malignant tumor has a poor survival rate. A number of genetic aberrations and somatic mutations have been associated with this kind of cancer. In recent times, the impact of long non-coding RNAs (IncRNAs) in glioblastoma has been underscored by several investigations. Up-regulation of a number of oncogenic IncRNAs such as H19, MALAT1, SNHGs, MIAT, UCA, HIF1AAS2 and XIST in addition to down-regulation of other tumor suppressor IncRNAs namely GAS5, RNCR3 and NBAT1 indicate the role of these IncRNAs in the pathogenesis of glioblastoma. Several in vitro and a number of in vivo studies have demonstrated the contribution of these transcripts in the regulation of cell proliferation and apoptosis, cell survival, invasion and metastasis of glioblastoma cells. Moreover, some IncRNAs such as SBF2-AS1 are involved in conferring resistance to temozolomide. Finally, few circularRNAs have been identified that influence the evolution of glioblastoma. In this paper, we discuss the impacts of IncRNAs in the pathogenesis of glioblastoma, their applications as markers and their implications in the therapeutic responses in this kind of cancer.

Keywords: IncRNA, circRNA, glioblastoma, expression, polymorphism

\section{INTRODUCTION}

Being considered as grade IV glioma tumors, glioblastomas are the utmost aggressive diffuse kind of glioma originating from the astrocytes, neural stem cells or progenitors (1). This type of brain tumor includes about half of all glioma tumors and less than $20 \%$ of all primary brain tumors (2). Although being a rare tumor, the poor prognosis and low survival rate of glioblastoma have made it an important public health problem (3). It is more frequent in men compared with females, in Western countries compared with developing world and in some ethnicities such as Asians, Latinos and Whites (3). The etiology of this kind of tumor is largely unclarified, as no causal carcinogen has been linked with it. High dose ionizing radiation is the solitary environmental element that is highly associated with risk of glioblastoma (4). A number of genetic aberrations such as activation of growth factor cascade through amplification and mutations in receptor tyrosine kinase genes, 
induction of the PI3K proteins and loss of the p53 and Rb tumor suppressor genes have been identified in glioblastoma (5). Genome-wide and direct sequencing techniques have also detected recurrent disease-causing mutations in glioblastoma samples in a number of genes such as IDH1 (6) and TERT promoter (7). Moreover, contemporary studies have conveyed anomalous expression of long non-coding RNAs (lncRNAs) in glioblastoma samples indicating the impact of these transcripts in the pathobiology of this kind of cancer (8). These transcripts are larger than 200 nucleotides and regulate expression of numerous genes at transcriptional, post-transcriptional, and epigenetic phases (9). In the current paper, we discuss the impact of lncRNAs in the pathobiology of glioblastoma and their effects on the regulation of cell proliferation and apoptosis, cell survival, invasion and metastatic aptitude of glioblastoma cells.

\section{ONCOGENIC LNCRNAS IN GLIOBLASTOMA}

Several oncogenic lncRNAs have been up-regulated in glioblastoma samples. For instance, MIR22HG is an oncogenic lncRNA which has been shown to be highly dysregulated in glioblastoma via assessment of accessible datasets. This lncRNA hosts miR-22-3p and miR-22-5p. Further studies have unraveled over-expression of the MIR22HG/miR-22 route in glioblastoma and glioma stem-like cells. Over-expression of MIR22HG in glioblastoma samples has been related with poor patients' outcome. Knock down of this lncRNA has led to inactivation of the Wnt/ $\beta$-catenin route via modulating miR-22-3p and miR22-5p expressions. Functionally, MIR22HG silencing has diminished cell proliferation, invasion and tumor growth in xenograft models. The mentioned miRNAs have been shown to target SFRP2 and PCDH15. Taken together, MIR22HG has been acknowledged as an important activator of the $\mathrm{Wnt} / \beta$ catenin signaling pathway, and its silencing has been proposed as a therapeutic modality in this kind of cancer (10). The small nucleolar RNA host gene 5 (SNHG5) is another up-regulated lncRNA in glioblastoma which enhances cell proliferation and suppresses cell apoptosis in these cells. Expression of this lncRNA is activated by the Yin Yang 1 (YY1) transcription factor. This lncRNA exerts its oncogenic role via stimulation of the p38/MAPK axis (11). SNHG9 has also been demonstrated to be over-expressed in glioblastoma samples in association with poor survival of patients. SNHG9 has a role in suppression of miR-199a-5p expression and enhancement of Wnt2 expression in glioblastoma cells. This lncRNA has been revealed to enhance aerobic glycolysis and cell proliferation (12). Expression of SAMMSON has been increased in the plasma of patients with glioblastoma but not in those with diffuse neurosarcoidosis, a disorder that shares MRI signs with glioblastoma. This lncRNA has been displayed to suppress expression of miR-622 in glioblastoma cells and subsequently enhance cell (13). MIAT is another up-regulated lncRNA in glioblastoma. Bountali et al. have knocked down this lncRNA in glioblastoma cell lines and analyzed RNA profile of these cells via RNA sequencing method.
They reported differential expression of several genes including those participating in cancer-associated functions, namely cell growth and viability, apoptotic features, reactive oxygen species creation and migration. Functionally, MIAT silencing abolishes long-term viability and migration and enhances apoptosis in these cells (14). A genome-wide expression profiling in glioblastoma cells has identified MALAT1 as one of the most remarkably over-expressed genes following treatment with temozolomide (TMZ). Expression of this lncRNA has been coregulated by $\mathrm{p} 50$ and $\mathrm{p} 53$ through $\mathrm{\kappa B}$ - and p53-binding sites which are located in coding sequence of this lncRNA. MALAT1 silencing has increased sensitivity of patient-originated glioblastoma cells to TMZ and improved the effects of this drug in xenograft mice models (15). UCA1 is another oncogenic lncRNA which enhances cell proliferation and migration, while suppressing cell apoptosis. Figure 1 depicts the molecular mechanisms through which UCA1 participates in the pathogenesis of glioblastoma.

Table 1 reviews the function of oncogenic lncRNAs in glioblastoma.

\section{TUMOR SUPPRESSOR LNCRNAS IN GLIOBLASTOMA}

Expression of GAS5 has been decreased in glioblastoma and its levels have been negatively correlated with miR-34a levels (61). In addition, expression of AC016405.3 has been decreased in glioblastoma tissues in association with numerous aggressive characteristics of this type of cancer. Up-regulation of this lncRNA inhibits proliferation and metastatic ability of glioblastoma cells. The oncogenic miRNA, miR-19a-5p has been identified as a downstream miRNA of AC016405.3. AC016405.3 has been shown to be targeted by miR-19a-5p. Functionally, AC016405.3 inhibits cell proliferation and metastasis via regulation of TET2 by serving as a sponge for miR-19a-5p (62). LINC00657 is another tumor suppressor lncRNA whose expression has been decreased in glioblastoma sections compared with neighboring normal section. Upregulation of this lncRNA has suppressed cell proliferation, colony formation, invasiveness and migratory potential of glioma cells through activating cell apoptosis. LINC00657 has been acknowledged as a direct target of miR-190a-3p, a miRNA that negatively regulates PTEN expression. The tumor suppressive role of LINC00657 has also been verified in xenograft models (63). The lncRNA AC003092.1 has been shown to be down-regulated in TMZ resistance cells compared with their original cells. Moreover, down-regulation of this lncRNA has been correlated with resistance to TMZ, higher possibility of tumor relapse, and poor patients' outcome. Cell line studies has shown improvement of TMZ sensitivity following up-regulation of AC003092.1. The effect of this lncRNA in the modulation of TMZ sensitivity is exerted via regulation of TFPI2-associated cell apoptosis through sponging miR-195 (64). RNCR3 is another down-regulated lncRNA in glioblastoma. Over-expression of this lncRNA significantly suppresses cell 


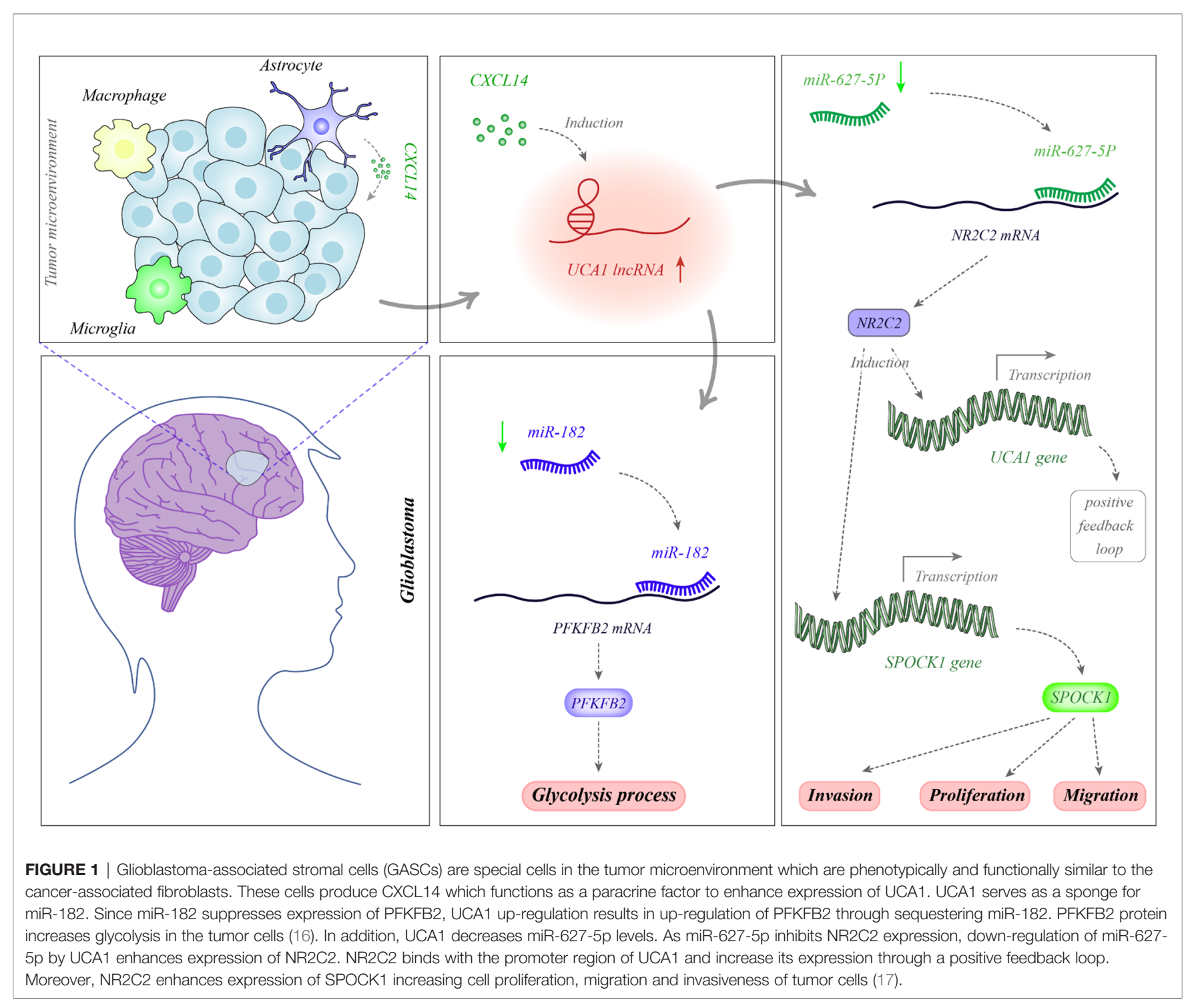

survival and proliferation of glioblastoma cells, while enhancing cell apoptosis and activity caspase-3/7. Besides, up-regulation of this lncRNA enhances expression of Krüppel-like factor 16 (KLF16) via suppressing miR-185-5p (65). Table 2 gives an outline of studies which assessed function of tumor suppressor lncRNAs in glioblastoma.

\section{DIAGNOSTIC AND PROGNOSTIC VALUE OF LNCRNAS IN GLIOBLASTOMA}

Expression levels of lncRNAs can distinguish patients with glioblastoma from cancer-free individuals. Moreover, these transcripts can possibly differentiate different brain tumors. For instance, plasma levels of SAMMSON can differentiate glioblastoma from both diffuse neurosarcoidosis and healthy controls (13). Among lncRNAs whose diagnostic power has been assessed in glioblastoma, HOTAIR has exhibited the most promising results.
Tan et al. have demonstrated significant higher levels of this lncRNA in sera of glioblastoma patients compared with controls. The area under the receiver operating characteristic (ROC) curve was 0.913 indicating the ideal feature of HOTAIR for this purpose. Moreover, they reported significant correlation between its levels and high tumor grade. Notably, there was significant correlation between tumor and serum levels of this lncRNA. Finally, exosomes extracted from the serum samples have been shown to contain this lncRNA, further emphasizing the application of this lncRNA in the prognostic and diagnostic processes in glioblastoma (49). In addition, Kaplan-Meier analysis has indicated the correlation between expression levels of several lncRNAs such as SNHG9, TRG-AS1, AGAP2-AS1, lnc-TALC, SBF2-AS1, SNHG20, AC016405.3, LINC-ROR, HOXB-AS1, H19, LINC00152, RAMP2-AS1 and GAS5 and patients' prognosis in the terms of overall survival, disease-free survival and progression free survival. Table 3 gives a summary of studies which assessed such aspect of lncRNAs in glioblastoma. 
TABLE 1 | List of over-expressed IncRNAs in glioblastoma.

\begin{tabular}{|c|c|c|c|c|c|c|c|}
\hline IncRNA & Patients' specimens & Cell line & $\begin{array}{l}\text { Targets/ } \\
\text { Regulators }\end{array}$ & $\begin{array}{l}\text { Signaling } \\
\text { pathways }\end{array}$ & Functional impact & $\begin{array}{l}\text { Impact of high expression } \\
\text { on patient's prognosis }\end{array}$ & Reference \\
\hline $\mathrm{MIR} 22 \mathrm{HG}$ & 18 gliomas and 5 NBT & $\begin{array}{l}\text { U87MG, LN229, and } \\
\text { LN18 }\end{array}$ & $\begin{array}{l}\text { b-catenin, miR- } \\
\text { 22-3p, SFRP2, } \\
\text { PCDH15 }\end{array}$ & Wnt & $\begin{array}{l}\text { MIR22HG is over-expressed in glioma and glioma } \\
\text { stem-like cells. Its silencing constrains the Wnt/b- } \\
\text { catenin axis via loss of miR-22-3p and }-5 p \text {. This } \\
\text { diminishes proliferation, invasion and tumor growth. }\end{array}$ & poor survival & (10) \\
\hline SNHG5 & - & $\begin{array}{l}\text { U251, U87, LN229 and } \\
\text { HEB }\end{array}$ & $\begin{array}{l}\text { ELK1, caspase- } \\
3, \text { STAT1, p-p38/ } \\
\text { YY1, TNF-a }\end{array}$ & p38/MAPK & $\begin{array}{l}\text { SNHG5 enhances GBM proliferation and suppresses } \\
\text { apoptosis in GBM. YY1 is the activator of SNHG5 } \\
\text { transcription in GBM. }\end{array}$ & - & (11) \\
\hline SNHG9 & - & U87 and U251 & $\begin{array}{l}\text { miR-199a-5p } \\
\text { and Wnt2 }\end{array}$ & Wnt/b-catenin & $\begin{array}{l}\text { SNHG9 enhances aerobic glycolysis and cell } \\
\text { proliferation, which can be weakened by miR-199a- } \\
5 \text { p. }\end{array}$ & lower survival rate & (12) \\
\hline SAMMSON & $\begin{array}{l}56 \text { patients with GBM, } 34 \text { patients } \\
\text { with diffuse neurosarcoidosis and } \\
35 \text { healthy controls }\end{array}$ & U87, U-373 & miR-622 & - & $\begin{array}{l}\text { SAMMSON overexpression down-regulates miR-622 } \\
\text { and increases proliferation rate. }\end{array}$ & - & (13) \\
\hline DLEU1 & $\begin{array}{l}10 \text { GBM tissues and } 10 \text { adjacent } \\
\text { NBT }\end{array}$ & SHG-44, U251 & TRA F4 & - & $\begin{array}{l}\text { Over-expression of DLEU enhances viability and cell } \\
\text { proliferation. }\end{array}$ & - & (18) \\
\hline TRG-AS1 & 51 glioma tissues and 51 NBTs & $\begin{array}{l}\text { U251, U87, A172, } \\
\text { LN229, NHAs }\end{array}$ & miR-877-5p & - & $\begin{array}{l}\text { TRG-AS1 inhibits miR-877-5p while miR-877-5p } \\
\text { inhibits SUZ12 expression. }\end{array}$ & poor prognosis & (19) \\
\hline LINC01579 & $\begin{array}{l}51 \text { patients with } \\
\text { GBM }\end{array}$ & $\begin{array}{l}\text { U251, U87, U87MG, } \\
\text { LN229, NHA }\end{array}$ & miR-139-5p & - & $\begin{array}{l}\text { LINC01579 regulates cell proliferation and apoptosis } \\
\text { through binding with miR-139-5p. }\end{array}$ & - & (20) \\
\hline AGAP2-AS1 & 58 GBM patients & $\begin{array}{l}\text { A172, U87/MG, U251/ } \\
\text { MG, LN229, SHG44, } \\
\text { NHA }\end{array}$ & $\mathrm{EZH} 2$ and LSD1 & - & $\begin{array}{l}\text { Up-regulation of AGAP2-AS1 enhances cell } \\
\text { proliferation and apoptosis. }\end{array}$ & Poor prognosis & (21) \\
\hline Inc-TALC & 79 GBM patients & $\begin{array}{l}\text { LN229, U251, 551W, } \\
\text { HG7, 229R, 251R, } \\
\text { 551WR, HG7R }\end{array}$ & $\begin{array}{l}\text { miR-20b-3p/ } \\
\text { phosphorylated } \\
\text { AKT/FOXO3 axis }\end{array}$ & c-MET & $\begin{array}{l}\text { Inc-TALC is associated with TMZ resistance through } \\
\text { interacting with miR-20b-3p to enhance c-Met } \\
\text { expression. }\end{array}$ & $\begin{array}{l}\text { Low Inc-TALC expression } \\
\text { improved prognosis after } \\
\text { receiving TMZ. }\end{array}$ & (22) \\
\hline LncSBF2-AS1 & $\begin{array}{l}20 \text { primary and their corresponding } \\
\text { recurrent GBM specimens (each } \\
\text { pair from the same patient who was } \\
\text { under TMZ treatment) }\end{array}$ & $\begin{array}{l}\text { U87, LN229, A172, } \\
\text { T98, U251, HEK293T, } \\
\text { N3 primary culture cell }\end{array}$ & $\begin{array}{l}\text { miR-151a-3p/ } \\
\text { ZEB1 }\end{array}$ & - & $\begin{array}{l}\text { SBF2-AS1 is up-regulated in TMZ-resistant GBM } \\
\text { cells and tissues. }\end{array}$ & $\begin{array}{l}\text { Recurrent } \\
\text { GBM patients cases with } \\
\text { high serum exosomal SBF2- } \\
\text { AS1 amounts had poor } \\
\text { outcome and a resistance to } \\
\text { TMZ. }\end{array}$ & (23) \\
\hline SNHG2O & $\begin{array}{l}78 \text { pairs of human glioblastoma } \\
\text { tissues and adjacent tissues }\end{array}$ & $\begin{array}{l}\text { U87MG, U343, U251, } \\
\text { LN215, NHA }\end{array}$ & $\begin{array}{l}\text { Cyclin D1, CDK4, } \\
\text { caspase } 9 \text {, PI3K, } \\
\text { Akt and mTOR }\end{array}$ & $\begin{array}{l}\text { PI3K/Akt/ } \\
\text { mTOR }\end{array}$ & $\begin{array}{l}\text { SNHG20 overexpression enhanced cell proliferation, } \\
\text { decreased apoptosis and increased stem properties. }\end{array}$ & Low survival rate & (24) \\
\hline \multirow[t]{4}{*}{ MALAT1 } & $\begin{array}{l}\text { Patients expressing MALAt1 were } \\
\text { separated into two low }(n=19) \text { and } \\
\text { high }(n=15) \text { expressing groups }\end{array}$ & $\begin{array}{l}\text { U87, A172, and U251, } \\
\text { patient-derived GSCs, } \\
\text { GBM34 and GBM44 }\end{array}$ & -/p50 and p52 & $\mathrm{NF}-\kappa \mathrm{B}$ & MALAT1 silencing sensitizes GBM cells to TMZ. & - & (15) \\
\hline & - & U251, U87 & $\begin{array}{l}\text { ZEB1, MDR1, } \\
\text { MRP5, LRP1 }\end{array}$ & - & $\begin{array}{l}\text { MALAT1silencing down-regulated MDR1, MRP5, and } \\
\text { LRP1 levels, increased response to TMZ, and } \\
\text { decreased ZEB1 level. }\end{array}$ & - & (25) \\
\hline & - & U251 & $\begin{array}{l}\text { miR-101, } \\
\text { GSK3ß, MGMT }\end{array}$ & - & $\begin{array}{l}\text { MALAT1 levels were higher in TMZ-resistant GBM } \\
\text { cells. MALAT1 silencing reduces TMZ resistance by } \\
\text { inhibiting cell proliferation and promoting apoptosis. }\end{array}$ & - & (26) \\
\hline & $\begin{array}{l}140 \text { GBM patients: } 70 \text { responsive } \\
\text { to TMZ and } 70 \text { non-responsive }\end{array}$ & U87, U251 & miR-203, TS & - & $\begin{array}{l}\text { MALAT1 induces resistance to TMZ via inhibiting } \\
\text { miR-203 and enhancing thymidylate synthase } \\
\text { expression. }\end{array}$ & Poor OS and RFS & (27) \\
\hline
\end{tabular}




\begin{tabular}{|c|c|c|c|c|c|c|c|}
\hline IncRNA & Patients' specimens & Cell line & $\begin{array}{l}\text { Targets/ } \\
\text { Regulators }\end{array}$ & $\begin{array}{l}\text { Signaling } \\
\text { pathways }\end{array}$ & Functional impact & $\begin{array}{l}\text { Impact of high expression } \\
\text { on patient's prognosis }\end{array}$ & Reference \\
\hline miR155HG & $\begin{array}{l}24 \text { GBM tissues and } 15 \text { adjacent } \\
\text { NBTs }\end{array}$ & $\begin{array}{l}\text { normal human } \\
\text { astrocyte cell line NHA, } \\
\text { U87, U251, Ln229, } \\
\text { T98, and A172, GP1 } \\
\text { and GP2 }\end{array}$ & $\begin{array}{l}\text { miR-185/ANXA2, } \\
\text { STAT3 }\end{array}$ & PI3K-Akt & $\begin{array}{l}\text { miR155HG enhances epithelial-to-mesenchymal } \\
\text { transition in glioma. miR155HG silencing inhibited } \\
\text { GBM cell proliferation, stimulated G1/S-phase cell } \\
\text { cycle arrest, and enhanced apoptosis. }\end{array}$ & - & (28) \\
\hline TP73-AS1 & $\begin{array}{l}\text { TCGA and GTEx datasets: } 207 \\
\text { normal, } 518 \text { low grade glioma and } \\
163 \text { GBM }\end{array}$ & G26 and G7 & $\mathrm{ALDH} 1 \mathrm{~A} 1$ & - & $\begin{array}{l}\text { TP73-AS1 increases TMZ resistance in GBM cancer } \\
\text { stem cells and enhances tumor aggressiveness. }\end{array}$ & Poor prognosis & (29) \\
\hline LINC-ROR & 57 GBM tissues and 10 NBTs & - & $\begin{array}{l}\text { caspase } 3 \\
\text { and p53 }\end{array}$ & - & $\begin{array}{l}\text { Patients with OS less than } 15 \text { months had up- } \\
\text { regulation of LINC-ROR. }\end{array}$ & poor PDF and overall survival & (30) \\
\hline MIAT & - & $\begin{array}{l}\text { SH-SY5Y, GBM } \\
1321 \mathrm{~N} 1 \\
\text { GBMT98G }\end{array}$ & Many genes & $\begin{array}{l}\text { MAPK, } \\
\text { Phospholipase } \\
\text { D, TGF- } \beta \text {, } \\
\text { NOD-like } \\
\text { receptor, EGFR }\end{array}$ & $\begin{array}{l}\text { MIAT enhances cell growth, survival, production of } \\
\text { reactive oxygen species and migration, and } \\
\text { decreases basal apoptosis. }\end{array}$ & - & (14) \\
\hline HOXB-AS1 & $\begin{array}{l}486 \text { low grade glioma (LGG) and } \\
154 \text { glioblastoma (GBM) tissues }\end{array}$ & $\begin{array}{l}\text { HA, LN229, U87 and } \\
\text { U251 cell lines }\end{array}$ & $\begin{array}{l}\text { miR-885-3p, } \\
\text { HOXB2 }\end{array}$ & & $\begin{array}{l}\text { HOXB-AS1silencing suppresses cell proliferation } \\
\text { through inducing } \mathrm{S} \text { phase cell cycle arrest, and } \\
\text { suppresses the migration and invasion capacity. }\end{array}$ & Poor prognosis & (31) \\
\hline GAPLINC & $\begin{array}{l}\text { High GAPLINC expressing group } \\
(\mathrm{n}=80) \text { and low GAPLINC } \\
\text { expressing group }(\mathrm{n}=81)\end{array}$ & $\begin{array}{l}\text { NHAs, T98G, U251, } \\
\text { LN18, LN229, and } \\
\text { A172 }\end{array}$ & miR-331-3p & - & $\begin{array}{l}\text { GAPLINC enhances GBM cells proliferation, } \\
\text { migration, and invasion, and reduces apoptosis. }\end{array}$ & $\begin{array}{l}\text { shorter overall } \\
\text { survival and disease-free } \\
\text { survival }\end{array}$ & (32) \\
\hline \multirow[t]{2}{*}{ AHIF } & - & $\begin{array}{l}\text { U87-MG and T98G } \\
\text { GBM cell }\end{array}$ & $\begin{array}{l}\text { Bax, Bcl-2, and } \\
\text { caspase } 7\end{array}$ & - & $\begin{array}{l}\text { AHIF was up-regulated in GBM cells after } \\
\text { radiotherapy and affects GBM cell clonogenic } \\
\text { formation, DNA repair and apoptosis. }\end{array}$ & - & (33) \\
\hline & $\begin{array}{l}31 \text { GBM patients and } 7 \text { adjacent } \\
\text { NBT }\end{array}$ & $\begin{array}{l}\text { U87-MG, U251-MG, } \\
\text { A172, T98G }\end{array}$ & $\begin{array}{l}\text { VEGF, } \\
\text { angiogenin, Bcl- } \\
\text { 2, Bcl-xl, Mcl-1 }\end{array}$ & - & $\begin{array}{l}\text { AHIF enhances viability and invasiveness, and } \\
\text { reduced the proportion of apoptotic cells. Exosomes } \\
\text { originated from AHIF-overexpressing GBM cells } \\
\text { enhanced viability, invasion and radio-resistance. }\end{array}$ & - & (34) \\
\hline AGAP2-AS1 & $\begin{array}{l}116 \text { GBM tissues, } 20 \text { low-grade } \\
\text { glioma samples and } 20 \text { adjacent } \\
\text { NBTs }\end{array}$ & $\begin{array}{l}\text { U87, U251, human } \\
\text { astrocyte cell line }(\mathrm{HA})\end{array}$ & - & - & $\begin{array}{l}\text { Up-regulation of AGAP2-AS1 enhances cell } \\
\text { proliferation, migration, and invasion, but reduces cell } \\
\text { apoptosis. }\end{array}$ & Shorter overall survival & (35) \\
\hline \multirow[t]{2}{*}{ Inc-UCA1 } & $\begin{array}{l}\text { Glioma samples: Grade I-II }(n=5) \text {, } \\
\text { Grade III-IV }(n=5) \text { and normal } \\
\text { human brain tissues }(n=5)\end{array}$ & $\begin{array}{l}\text { Human U87 and U251 } \\
\text { glioma cell }\end{array}$ & $\begin{array}{l}\text { miR-627-5p, } \\
\text { NR2C2 }\end{array}$ & - & $\begin{array}{l}\text { UCA1 overexpression enhances proliferation, } \\
\text { migration, and invasion, but suppresses apoptosis. }\end{array}$ & - & (17) \\
\hline & 42 paired glioma tissues and NBTs & U251, U87MG & $\begin{array}{l}\text { miR-182, } \\
\text { PFKFB2/CXCL14 }\end{array}$ & - & $\begin{array}{l}\text { UCA1/miR-182/PFKFB2 axis induces glycolysis and } \\
\text { invasion. }\end{array}$ & Poor survival & (16) \\
\hline \multirow[t]{3}{*}{ H19 } & $\begin{array}{l}50 \text { FFPE brain tissue from GBM } \\
\text { patients and } 10 \text { cancer-free brain } \\
\text { tissue samples }\end{array}$ & - & miR-326 & - & $\begin{array}{l}\text { H19 over-expression confers poor OS and } \\
\text { progression-free survival. }\end{array}$ & Poor OS & (36) \\
\hline & - & $\begin{array}{l}\text { U87, U251, Ln229, } \\
\text { U373, U118, GP1, GP2 }\end{array}$ & $\begin{array}{l}\operatorname{miR}-181 d, \beta- \\
\text { catenin/Hif-1 } \alpha \\
\text { PTEN, SP1 }\end{array}$ & - & $\begin{array}{l}\mathrm{H} 19 \text { expression is increased by Hif- } 1 \alpha \text { under } \\
\text { hypoxia. H19 contributes in hypoxia-associated } \\
\text { migration and invasion. }\end{array}$ & Lower survival rate & (37) \\
\hline & $\begin{array}{l}30 \text { glioblastoma tissues and } \\
\text { adjacent NBT }\end{array}$ & U87, U373, HUVECs & - & - & $\begin{array}{l}\text { H19 enhances glioblastoma cell invasion, } \\
\text { neurosphere formation, tumor growth and } \\
\text { angiogenesis. }\end{array}$ & Lower PFS & (38) \\
\hline
\end{tabular}




\begin{tabular}{|c|c|c|c|c|c|c|c|}
\hline IncRNA & Patients' specimens & Cell line & $\begin{array}{l}\text { Targets/ } \\
\text { Regulators }\end{array}$ & $\begin{array}{l}\text { Signaling } \\
\text { pathways }\end{array}$ & Functional impact & $\begin{array}{l}\text { Impact of high expression } \\
\text { on patient's prognosis }\end{array}$ & Reference \\
\hline & - & $\begin{array}{l}\text { U87MG, U251, U343, } \\
\text { Hs683, LN215, A172, } \\
\text { NHA }\end{array}$ & - & - & $\begin{array}{l}\text { H19 silencing reduced cellular proliferation and } \\
\text { increased apoptosis rate when induced by TMZ. } \\
\text { Cancer stem cell markers (CD133, Nanog, Oct- } 4 \text {, } \\
\text { and Sox2) are increased by H19 upregulation. }\end{array}$ & - & (39) \\
\hline \multirow[t]{3}{*}{ LINC00152 } & $\begin{array}{l}35 \text { samples ( } 5 \text { normal, } 10 \text { with } \\
\text { grade two, } 9 \text { with grade three and } \\
11 \text { with grade four GBM) }\end{array}$ & $\begin{array}{l}\text { LN229, U87-MG and } \\
\text { N9 (patient-derived } \\
\text { cells) }\end{array}$ & miR-612 & AKT2/NF-kB & $\begin{array}{l}\text { LINC00152 regulates malignant progression and } \\
\text { proneural-mesenchymal transition. }\end{array}$ & Poor prognosis & (40) \\
\hline & - & U87 & $\begin{array}{l}\text { TPM2, PTX3, } \\
\text { IGFBP4, TGM2, } \\
\text { SPP1, LUM }\end{array}$ & - & LINC00152 increases cellular invasion and EMT. & Poor survival & (41) \\
\hline & $\begin{array}{l}40 \text { glioblastoma samples and } \\
\text { matched NBTs }\end{array}$ & $\begin{array}{l}\text { U87, U251, LN229, } \\
\text { A172, U118, NHA }\end{array}$ & $\begin{array}{l}\text { E-cadherin, N- } \\
\text { cadherin, } \\
\text { Vimentin, and } \\
\text { Snail, HMGA2 }\end{array}$ & - & $\begin{array}{l}\text { LINC00152 enhances cell proliferation, EMT and } \\
\text { invasion. }\end{array}$ & - & (42) \\
\hline \multirow[t]{2}{*}{ LINC00470 } & 50 GBM samples and 10 NBTs & U251, U87 and U118 & $\begin{array}{l}\text { ELFN2, miR-101, } \\
\text { AurkA. and elF2a }\end{array}$ & & $\begin{array}{l}\text { LINC00470 increases expression of ELFN2 and } \\
\text { regulates methylation of ELFN2. LINCO0470 } \\
\text { suppresses ELFN2-induced GBM cell autophagy. }\end{array}$ & Poor prognosis & (43) \\
\hline & $\begin{array}{l}60 \text { astrocytoma tissues and } 12 \\
\text { NBT }\end{array}$ & U251, U87 & FUS and AKT & - & $\begin{array}{l}\text { Higher pAKT induced by LINC00470 decreased } \\
\text { ubiquitination of HK1 and suppressed autophagy. } \\
\text { Higher LINCO0470 expression was associated poor } \\
\text { patient outcome. }\end{array}$ & Poor prognosis & (44) \\
\hline LINC01446 & $\begin{array}{l}31 \text { pairs of GBM samples and } \\
\text { adjacent normal tissues }\end{array}$ & $\begin{array}{l}\text { NHA, A172, U87, U251 } \\
\text { and T98G }\end{array}$ & $\begin{array}{l}\text { miR-489-3p, } \\
\text { TPT1 }\end{array}$ & & $\begin{array}{l}\text { LINC01446 silencing suppressed GBM cell } \\
\text { proliferation, arrested cell-cycle progression, } \\
\text { decreased tumor growth and attenuated invasion. }\end{array}$ & poor prognosis and OS & (45) \\
\hline CASP5 & 40 pairs of GBM and NBTs & $\begin{array}{l}\text { A172, U87MG, } \\
\text { U251MG, T98G, } \\
\text { U118MG and the } \\
\text { human astrocyte cell } \\
\text { line HA }\end{array}$ & $\begin{array}{l}\text { Cyclin D1, MMP- } \\
9, \text { MMP-2, E- } \\
\text { cadherin, N- } \\
\text { cadherin, and } \\
\text { Vimentin }\end{array}$ & - & $\begin{array}{l}\text { CASP5 silencing has suppressed GBM proliferation } \\
\text { and arrested cells in G1. }\end{array}$ & - & (46) \\
\hline LOXL1-AS1 & $\begin{array}{l}169 \text { GBM RNA-seq data (68 MES } \\
\text { and } 101 \text { PN) }\end{array}$ & U87MG & RELB & NF-kB & $\begin{array}{l}\text { GBM cell proliferation was inhibited by LOXL1-AS1 } \\
\text { silencing. }\end{array}$ & Poor prognosis and low OS & $(47)$ \\
\hline MNX1-AS1 & $\begin{array}{l}44 \text { pairs of GBM samples and } \\
\text { adjacent normal tissues }\end{array}$ & $\begin{array}{l}\text { U138, LN229, T98, } \\
\text { U251 }\end{array}$ & $m i R-4443$ & - & $\begin{array}{l}\text { MNX1-AS1 enhanced the proliferation, migration, and } \\
\text { invasion of GBM cells. }\end{array}$ & - & (48) \\
\hline \multirow[t]{3}{*}{ HOTAIR } & $43 \mathrm{GBM}$ patients and 40 controls & - & - & - & $\begin{array}{l}\text { HOTAIR expression correlates with high grade brain } \\
\text { tumors. }\end{array}$ & - & (49) \\
\hline & $\begin{array}{l}123 \text { GBM cases from TCGA, } 34 \\
\text { cases from CGGA2, } 227 \text { cases } \\
\text { from Rembrandt, } 79 \text { cases from } \\
\text { Tseq, and } 77 \text { cases from } \\
\text { GSE4290 }\end{array}$ & U87, U87vill & NLK & $\beta$-catenin & $\begin{array}{l}\text { HOTAIR silencing suppressed GBM cell migration } \\
\text { and invasion. }\end{array}$ & Poorer survival & (50) \\
\hline & TCGA dataset: 220 glioma & U87, LN229 & $\mathrm{EZH} 2$ & - & HOTAIR enhances cell cycle progression. & Lower survival & (51) \\
\hline SNHG7 & 53 pairs of GBM tissues and NBTs & $\begin{array}{l}\text { HEB, A172, U87, } \\
\text { T98G, SHG44 }\end{array}$ & miR-5095 & Wnt/b-catenin & $\begin{array}{l}\text { SNHG7 silencing inhibited proliferation, migration and } \\
\text { invasion and induced apoptosis. }\end{array}$ & Poorer prognosis & (52) \\
\hline
\end{tabular}




\begin{tabular}{|c|c|c|c|c|c|c|c|}
\hline IncRNA & Patients' specimens & Cell line & $\begin{array}{l}\text { Targets/ } \\
\text { Regulators }\end{array}$ & $\begin{array}{l}\text { Signaling } \\
\text { pathways }\end{array}$ & Functional impact & $\begin{array}{l}\text { Impact of high expression } \\
\text { on patient's prognosis }\end{array}$ & Reference \\
\hline \multirow[t]{2}{*}{ NEAT1 } & - & $\begin{array}{l}\mathrm{N} 5, \mathrm{~N} 9 \text { and N33 } \\
\text { patient-derived cells }\end{array}$ & $\begin{array}{l}\text { b-catenin, ICAT, } \\
\text { GSK3B, Axin2, } \\
\text { EZH2/STAT3, } \\
\text { p65 }\end{array}$ & $\begin{array}{l}\text { WNT/b-catenin, } \\
\text { EGFR, NFkB }\end{array}$ & $\begin{array}{l}\text { NEAT1 enhances proliferation, clone formation, and } \\
\text { invasion but suppresses cell apoptosis. }\end{array}$ & - & (53) \\
\hline & 120 glioma tissues and 30 NBTs & $\begin{array}{l}\text { U87, T98G, U251, } \\
\text { A272, U373, HEK293T }\end{array}$ & $\begin{array}{l}\text { miR-let7e, } \\
\text { Argonaute 2, } \\
\text { NRAS }\end{array}$ & - & $\begin{array}{l}\text { NEAT1 silencing suppressed GSC cell proliferation, } \\
\text { migration and invasion and promoted GSC } \\
\text { apoptosis. }\end{array}$ & - & (54) \\
\hline SOX2OT & $\begin{array}{l}\text { Human glioma tissues (grade } \\
\text { one }=5 \text {, grade two }=5 \text {, grade } \\
\text { three }=8 \text {, grade four }=8 \text { ) and } 5 \text { NBTs }\end{array}$ & U87 and U251 & $\begin{array}{l}\text { miR-194-5p and } \\
\text { miR-122/SOX3 }\end{array}$ & JAK/STAT & $\begin{array}{l}\text { SOX2OT promoted the proliferation, migration and } \\
\text { invasion of GSCs, and inhibited GSCs apoptosis. }\end{array}$ & - & (55) \\
\hline TUG1 & $\begin{array}{l}20 \text { GBM specimens (grade one to } \\
\text { four, each 5) and } 5 \text { normal brain } \\
\text { tissues }\end{array}$ & $\begin{array}{l}\text { U251 MG, U87MG, } \\
\text { 293T }\end{array}$ & miR-299, VEGFA & - & $\begin{array}{l}\text { TUG1 promotes tumor-induced endothelial cell } \\
\text { proliferation, migration and tube formation and } \\
\text { enhances spheroid-based angiogenesis. }\end{array}$ & - & (56) \\
\hline HIF1A-AS2 & - & Primary human GSCs & $\begin{array}{l}\text { IGF2BP2, DHX9, } \\
\text { HMGA1 }\end{array}$ & - & $\begin{array}{l}\text { This IncRNA regulates GSC growth, self-renewal, } \\
\text { hypoxia-associated molecular reprogramming and } \\
\text { adaptation to hypoxia within the tumor niche. }\end{array}$ & Poor OS & $(57)$ \\
\hline XIST & - & $\begin{array}{l}\text { Human embryonic } \\
\text { kidney (HEK) 293T cells }\end{array}$ & miR-152 & - & $\begin{array}{l}\text { XIST promotes cell proliferation, migration and } \\
\text { invasion and suppresses apoptosis. }\end{array}$ & - & (58) \\
\hline MCMЗAP-AS & 422 GBM patients (TCGA dataset) & - & МСМЗАР & - & $\begin{array}{l}\text { MCM3AP-AS corresponds to the coding-gene } \\
\text { MCM3AP, which is involved in initiation of DNA } \\
\text { replication. }\end{array}$ & Lower OS & (59) \\
\hline LINC01057 & $\begin{array}{l}12 \text { paired frozen fresh GBM and } \\
\text { adjacent NBTs and the paraffin- } \\
\text { embedded human GBM samples }\end{array}$ & $\begin{array}{l}\text { LN229, T98G, } \\
\text { HEK293T }\end{array}$ & $\mathbb{I K K} \alpha$ & $\mathrm{NF}-\mathrm{\kappa B}$ & $\begin{array}{l}\text { LINC01057 up-regulation increases mesenchymal } \\
\text { differentiation in proneural cells. }\end{array}$ & - & (60) \\
\hline
\end{tabular}


TABLE 2 | List of under-expressed IncRNAs in glioblastoma.

Cell line

Targets/

Signaling

Functional role

Impact of low

expression on

patient's prognosis

AC016405.3 3 GBM samples and paired NBTs, 64 FFPE U87MG, U251MG miR-19a-5p, TET2 GBM specimens

AC016405.3 inhibits

Poor prognosis

LINC00657

40 pairs of GBM tissues and adjacent normal tissues

HA1800, U-87, LN-18,

proliferation and metastasis via affecting

(1)

108 human glioma tissue samples (75 grade IV, U87, U2

$\begin{array}{lll}\text { AC003092.1 } & 108 \text { human glioma tissue samples (75 grade IV, U87, U251 and their } \\ & 5 \text { grade III, } 13 \text { grade II, and } 15 \text { grade I } & \text { TMZ-resistant lines, }\end{array}$ astrocytoma cases)

U87TR and U251TR

GAS5

50 FFPE GB specimens and 10 NBTs

miR-190a-3p pTEN

suppresses viability and colony

Poor progonosis

formation in through increasing cell apoptosis.

Down-regulation of AC003092.1 correlates

Poor prognosis

with TMZ resistance, higher risk of relapse,

and poor outcome.

U87, U251, U373, A172 miR-185-5p, KLF16

AS5 level in reduced in GBM.

Poor overall survival

RNCR3 overexpression suppresses cell

survival and proliferation, enhances cell

apoptosis and activity of caspase-3/7.

NBAT1 down-regulation correlates with

proliferation ability, tumor size, degree of

OS and poor

high $=24$ expression of NBAT1) and 30 cases of U87, U373, T98, and

normal brain tissues

ᄂZ229

116 GBM specimens, 72 insensitive and $44 \quad$ U87

sensitive to TMZ treatment

TUSC7

20 GBM patients and adjacent normal tissue

U87 and U251

miR-10a

malignancy and cell viability.

RAMP2-AS1

53 patients: 38 GBM cases, 3 grade III

U87TR, U251TR, U87,

NOTCH3, P21,

Under-expression of TUSC7 confers resistant

prognosis

RP11-838N2.4 astrocytoma cases, 10 grade II astrocytoma U251

DHC10

to TMZ. cases, 2 grade I astrocytoma cases

enhances cell cycle progression.

Down-regulation of RP11-838N2.4 was

correlated with higher probability of tumor

GBM, glioblastoma multiform: TMZ, temozolomide: OS, overall sunvival: GSC, glioblastoma stem cell: FFPE, formalin-fixed, paraffin paraffin-embedded. 
TABLE 3 | Diagnostic/prognostic value of IncRNAs in glioblastoma.

Sample number

Area under curve

Sensitivity Specificity

Two groups of high and low SNHG9

OS and PFS in patients with high SNHG9

SNHG9 was an independent prognostic factor for

expressing patients, each contained 20

expression were lower than those with down-

worse OS.

regulation of SNHG9. High SNHG9 expression was

correlated with high tumor grade, greater tumor

56 patients with GBM, 34 patients with

GBM versus diffuse

dimension, and metastasis.

neurosarcoidosis: 0.92

controls/SAMMSON levels

GBM versus healthy

51 samples of glioma tissues

controls: 0.88

58 GBM patients

79 GBM patients

77 with high levels of SBF2-AS1 and 77 with low levels of SBF2-AS1

45 patients with low levels of SNHG2O and

33 patients with high levels of SNHG2O

Two groups of 32 patients with high and low

levels of AC016405.3

\section{7 glioblastoma patients}

LGG $(n=486)$ and $G M B(n=154)$

\section{6 glioma patients}

high $(n=37)$ and low $(n=38)$ AC003092.1

expression group

50 FFPE brain tissue from GBM patients

CGGA GBM (high expression $=45$ and low

expression= 45), TCGA GBM (high

expression $=77$ and low expression $=78$

Low group $(n=15)$ and high group $(n=16)$

15 patients with GBM/HOTAIR

53 patients with GBM 


\section{Sample number}

\section{Area under curve Sensitivity Specificity}

LINC00470 expression levels in two groups: high $=37$, low $=38$

7 low HOTAIR and 26 high HOTAIR (for survival), 22 low HOTAIR and 46 high

HOTAIR (for DFS), 10 high GAS5 and 23 low

GAS5 (for survival), 21 high GAS5 and 47

low GAS5 (for DFS)

Low (54) and high (54) groups of HOTAIR

expression (CGGA1 dataset)

$-$

High LINC00470 amounts were correlated with

LINC00470 levels, astrocytoma grade, age, and

shorter survival times and poor prognosis.

tumor site were associated with OS.

Patients with high HOTAIR and low GAS5 levels had

worse survival rates relative to patients with low

HOTAIR and high GAS5 levels.

Expression of $\mathrm{H} 19$ in two groups: high=14,

low $=16$

70 high and 70 low patients of MALAT1

expression

$-$

$-$

0.775
Low HOTAIR expression has increased OS.

- H19 over-expression was significantly associated

with a poor PFS.

71.51 62.82 MALAT1 over-expression was correlated with poor OS and RFS.
HOTAIR over-expression, age at diagnosis, IDH1 mutation, KPS score, and Ki-67 expression were associated with OS.

Serum MALAT1 levels and tumor grade were independent prognostic factors for OS of patients receiving TMZ.

GB, glioblastoma multiform; TMZ, temozolomide; OS, overall survival; PFS, progression-free survival; RFS, recurrence-free survival; DFS, disease-free survival.

TABLE 4 | List of circRNAs which participate in the development of glioblastoma.

\begin{tabular}{|c|c|c|c|c|c|c|c|c|}
\hline circRNA & $\begin{array}{l}\text { Pattern of } \\
\text { expression }\end{array}$ & $\begin{array}{l}\text { Patients' } \\
\text { specimens }\end{array}$ & Cell line & Targets/Regulators & $\begin{array}{l}\text { Signaling } \\
\text { pathways }\end{array}$ & Function & $\begin{array}{l}\text { Patient's } \\
\text { prognosis }\end{array}$ & Reference \\
\hline circNT5E & $\uparrow$ & $\begin{array}{l}39 \text { pairs of glioma } \\
\text { and NBTs }\end{array}$ & U87, U251 & miR-422a/ADARB2 & - & $\begin{array}{l}\text { circNT5E suppresses activity of miRNAs with tumor-suppressor like } \\
\text { features, and increase several pathologic processes, such as cell } \\
\text { proliferation, migration, and invasion. }\end{array}$ & - & (71) \\
\hline circ_0001946 & $\downarrow$ & - & U87, U251 & miR-671-5p, CDR1 & - & $\begin{array}{l}\text { Circ_0001946 inhibits expression of miR-671-5p, and increases CDR1 } \\
\text { levels. Circ_0001946 and CDR1 decrease proliferation, migration, and } \\
\text { invasion and upsurge apoptosis. }\end{array}$ & - & (73) \\
\hline circMTO1 & $\downarrow$ & $\begin{array}{l}59 \text { pairs of GBM } \\
\text { and NBTs }\end{array}$ & $\begin{array}{l}\text { NHA, A172, U251, } \\
\text { U87, SNB19, SHG44 }\end{array}$ & WWOX, miR-92 & - & $\begin{array}{l}\text { circMTO1 suppresses proliferation of tumorous cells. circMTO1 } \\
\text { increases expression of WWOX, and WWOX mediates circMTO1- } \\
\text { associated suppression of proliferation of U251 cells. circMTO1 directly } \\
\text { interact with miR-92. }\end{array}$ & Lower OS & (74) \\
\hline circ-PITX1 & $\uparrow$ & $\begin{array}{l}58 \text { pairs of GBM } \\
\text { and NBTs }\end{array}$ & $\begin{array}{l}\text { A172, LN229, U251, } \\
\text { U87, NHA }\end{array}$ & miR-379-5p, МАРЗК2 & MAPK & $\begin{array}{l}\text { Down-regulation of circ-PITX1 inhibits cell proliferation and enhances } \\
\text { cell apoptosis. }\end{array}$ & - & (75) \\
\hline hsa_circ_0076248 & $\uparrow$ & - & U251, U87, HEB & miR-181a, SIRT1, p53 & - & $\begin{array}{l}\text { hsa_circ_0076248 sponges miR-181a and down-regulates it. Down- } \\
\text { regulation of hsa_circ_0076248 depresses the proliferation and } \\
\text { invasion of glioma, and enhances the TMZ sensitivity. }\end{array}$ & - & (76) \\
\hline circMMP9 & $\uparrow$ & $\begin{array}{l}18 \text { pairs of GBM } \\
\text { and NBTs }\end{array}$ & U87, U251 & $\begin{array}{l}\text { miR-124, CDK4, } \\
\text { AURKAVIF4A3 }\end{array}$ & - & $\begin{array}{l}\text { circMMP9 enhances the proliferation, migration and invasion } \\
\text { capacities. }\end{array}$ & - & (77) \\
\hline circ_0074027 & $\uparrow$ & $\begin{array}{l}50 \text { pairs of GBM } \\
\text { and NBTs }\end{array}$ & $\begin{array}{l}\text { U87, U251, } \\
\text { A172, LN229, NHA }\end{array}$ & miR-518a-5p, IL17RD & - & $\begin{array}{l}\text { Cell growth, clone formation, migration and invasion were increased by } \\
\text { circ_0074027. }\end{array}$ & - & (78) \\
\hline
\end{tabular}

GBM, glioblastoma multiform; TMZ, temozolomide; OS, overall survival; NBT, normal brain tissue. 


\section{CIRCULAR RNAS AND GLIOBLASTOMA}

In addition to lncRNAs, Circular RNAs (circRNAs) can act as miRNA sponges to modulate expression of their target genes. Numerous studies have assessed expression and function of circRNAs in glioblastoma. For instance, Wang et al. have reported over-expression of some circRNAs and IncRNAs in miR-422adownregulated glioblastoma samples. They have also recognized a new circRNA originated from NT5E, termed circNT5E. Expression of this circRNA is modulated by ADARB2 through binding to sites neighboring circRNA-creating introns. circNT5E has been shown to regulate cell proliferation, migration, and invasion of glioblastoma cells through binding with miR-422a and suppressing its activity (71). $\mathrm{Li}$ et al. have demonstrated down-regulation of circ_0001946 and $C D R 1$, while up-regulation of miR-671-5p in glioblastoma cells. Circ_0001946 has been shown to inhibit expression of miR671-5p, therefore enhancing CDR1 expression. Circ_0001946 and CDR1 decrease cell proliferation, migration, and invasion and induce apoptosis in glioblastoma cells as verified by both in vitro and in vivo assays (72). Table 4 summarizes the expression and function of circRNAs in glioblastoma.

\section{DISCUSSION}

Both candidate gene and high throughput expression studies have reported anomalous expression of several lncRNAs in glioblastoma samples indicating the oncogenic roles for some lncRNAs and tumor suppressor roles for a number of other lncRNAs. Yet, the function of the former group of IncRNAs has been more assessed in this kind of cancer. Like other cancers, the role of lncRNAs in the pathogenesis of glioblastoma can be exerted through their effects on the expression of miRNAs. Accordingly, several lncRNA/miRNA/ mRNA axes have been identified in this context among them are SNHG9/miR-199a-5p/Wnt2, MIR155HG/miR-185/ANXA2, TRGAS1/miR-877-5p/SUZ12, LINC01579/miR-139-5p/EIF4G2, AC016405.3/miR-19a-5p/TET2, AC003092.1/miR-195/TFPI-2, LINC00657/miR-190a-3p/PTEN, RNCR3/miR-185-5p/KLF16, and MALAT1/miR-203/thymidylate synthase axes. Thus, comprehensive assessment of these three types of transcripts would facilitate identification of the molecular pathways underlying the pathogenesis of this type of cancer. Moreover, a number of recent studies revealed the role of circRNAs in regulation of expression of miRNAs, thus adding an extra level of complexity in gene regulation networks. An example of the circRNA/miRNA/

\section{REFERENCES}

1. Louis DN, Perry A, Reifenberger G, von Deimling A, Figarella-Branger D, Cavenee WK, et al. The 2016 World Health Organization Classification of Tumors of the Central Nervous System: a summary. Acta Neuropathol (2016) 131(6):803-20. doi: 10.1007/s00401-016-1545-1

2. Ostrom QT, Gittleman H, Farah P, Ondracek A, Chen Y, Wolinsky Y, et al. CBTRUS statistical report: Primary brain and central nervous system tumors diagnosed in the United States in 2006-2010. Neuro-oncology (2013) 15 Suppl 2(Suppl 2):ii1-56. doi: 10.1093/neuonc/not151

3. Hanif F, Muzaffar K, Perveen K, Malhi SM, Simjee SU. Glioblastoma Multiforme: A Review of its Epidemiology and Pathogenesis through
mRNA functional axis in glioblastoma is represented by circ_0001946/miR-671-5p/CDR1.

Association between lncRNA expression levels and resistance to TMZ has been assessed in several studies. Notably, expressions of oncogenic lncRNAs lnc-TALC, LncSBF2-AS1, MALAT1, TP73-AS1, and H19 as well as expression of tumor suppressor lncRNAs AC003092.1, TUSC7, and RP11-838N2.4 have been shown to alter this phenotype in glioblastoma cells. Therefore, a panel of these lncRNAs might be applied to predict response of pateints to this chemotherapeutic agent and establish a personalized strategy for these patients.

Finally, several oncogenic and tumor suppressor lncRNAs have been identified as modulators of glioblastoma patients' survival indicating the appropriateness of these transcripts as prognostic biomarkers. The diagnostic power of lncRNAs SAMMSON, HOTAIR, MALAT1, H19, and LINR-ROR has been assessed in serum or tissue samples of pateints with glioblastoma revealing the best results for the first two mentioned lncRNAs based on the high values of the area under the reciver operating characteristic curves. Considering the unavialbility of tissue samples for the purpose of early diagnosis and ambiguity of imaging techniques in early stages of the disease, assessment of expression of lncRNAs in serum samples provides a non-invasive method for early detection of this kind of malignant tumor.

In brief, dysregulation of several lncRNAs has been deteceted in glioblastoma cells leading to abnormal regualtion of cancerassociated pathways and cellular processes namely apoptosis, proliferation and survival. These transcripts provide promising tools for early detection of glioblastoma and prediction of patients' prognosis and response to therapeutic choices particularly TMZ. However, a limitation of in vitro studies in this regard is that most of them has been executed using traditional serum-grown cell lines such as U87 or U251. Furhther functional in vitro and in vivo investigations are required to verify the obtained data.

\section{AUTHOR CONTRIBUTIONS}

MT and SG-F wrote the draft and revised it. KHT, GS, and OR performed the data collection and designed the tables. All authors contributed to the article and approved the submitted version.

Clinical Presentation and Treatment. Asian Pac J Cancer Prev (2017) 18 (1):3-9. doi: 10.22034/APJCP.2017.18.1.3

4. Braganza MZ, Kitahara CM, Berrington de González A, Inskip PD, Johnson KJ, Rajaraman P. Ionizing radiation and the risk of brain and central nervous system tumors: a systematic review. Neuro-oncology (2012) 14(11):1316-24. doi: 10.1093/neuonc/nos208

5. Network CGAR. Comprehensive genomic characterization defines human glioblastoma genes and core pathways. Nature (2008) 455(7216):1061. doi: 10.1038 /nature07385

6. Parsons DW, Jones S, Zhang X, Lin JC-H, Leary RJ, Angenendt P, et al. An integrated genomic analysis of human glioblastoma multiforme. Science (2008) 321(5897):1807-12. doi: 10.1126/science.1164382 
7. Nonoguchi N, Ohta T, Oh J-E, Kim Y-H, Kleihues P, Ohgaki H. TERT promoter mutations in primary and secondary glioblastomas. Acta Neuropathol (2013) 126(6):931-7. doi: 10.1007/s00401-013-1163-0

8. Li J, Zhu Y, Wang H, Ji X. Targeting Long Noncoding RNA in Glioma: A Pathway Perspective. Mol Ther Nucleic Acids (2018) 13:431-41. doi: 10.1016/ j.omtn.2018.09.023

9. Mercer TR, Dinger ME, Mattick JS. Long non-coding RNAs: insights into functions. Nat Rev Genet (2009) 10(3):155-9. doi: 10.1038/nrg2521

10. Han M, Wang S, Fritah S, Wang X, Zhou W, Yang N, et al. Interfering with long non-coding RNA MIR22HG processing inhibits glioblastoma progression through suppression of Wnt/ $\beta$-catenin signalling. Brain (2020) 143(2):512-30. doi: 10.1093/brain/awz406

11. Chen L, Gong X, Huang M. YY1-activated long noncoding RNA SNHG5 promotes Glioblastoma cell proliferation through p38/MAPK signaling pathway. Cancer Biother Radiopharm (2019) 34(9):589-96. doi: 10.1089/cbr.2019.2779

12. Zhang H, Qin D, Jiang Z, Zhang J. SNHG9/miR-199a-5p/Wnt2 axis regulates cell growth and aerobic glycolysis in glioblastoma. J Neuropathol Exp Neurol (2019) 78(10):939-48. doi: 10.1093/jnen/nlz078

13. Xie J, Wang X, Liu S, Chen C, Jiang F, Mao K, et al. LncRNA SAMMSON overexpression distinguished glioblastoma patients from patients with diffuse neurosarcoidosis. NeuroReport (2019) 30(12):817-21. doi: 10.1097/ WNR.0000000000001278

14. Bountali A, Tonge DP, Mourtada-Maarabouni M. RNA sequencing reveals a key role for the long non-coding RNA MIAT in regulating neuroblastoma and glioblastoma cell fate. Int J Biol Macromol (2019) 130:878-91. doi: 10.1016/ j.ijbiomac.2019.03.005

15. Voce DJ, Bernal GM, Wu L, Crawley CD, Zhang W, Mansour NM, et al. Temozolomide treatment induces lncRNA MALAT1 in an NF- $\kappa B$ and $\mathrm{p} 53$ codependent manner in glioblastoma. Cancer Res (2019) 79(10):2536-48. doi: 10.1158/0008-5472.CAN-18-2170

16. He Z, You C, Zhao D. Long non-coding RNA UCA1/miR-182/PFKFB2 axis modulates glioblastoma-associated stromal cells-mediated glycolysis and invasion of glioma cells. Biochem Biophys Res Commun (2018) 500(3):56976. doi: 10.1016/j.bbrc.2018.04.091

17. Fan Z, Zheng J, Xue Y, Liu X, Wang D, Yang C, et al. NR2C2-uORF targeting UCA1-miR-627-5p-NR2C2 feedback loop to regulate the malignant behaviors of glioma cells. Cell Death Dis (2018) 9(12):1-18. doi: 10.1038/s41419-018-1149-x

18. Wang J, Quan X, Peng D, Hu G. Long non-coding RNA DLEU1 promotes cell proliferation of glioblastoma multiforme. Mol Med Rep (2019) 20 (2):1873-82. doi: 10.3892/mmr.2019.10428

19. Xie H, Shi S, Chen Q, Chen Z. LncRNA TRG-AS1 promotes glioblastoma cell proliferation by competitively binding with miR-877-5p to regulate SUZ12 expression. Pathol-Res Pract (2019) 215(8):152476. doi: 10.1016/j.prp.2019.152476

20. Chai Y, Xie M. LINC01579 promotes cell proliferation by acting as a ceRNA of miR-139-5p to upregulate EIF4G2 expression in glioblastoma. J Cell Physiol (2019) 234(12):23658-66. doi: 10.1002/jcp.28933

21. Luo W, Li X, Song Z, Zhu X, Zhao S. Long non-coding RNA AGAP2-AS1 exerts oncogenic properties in glioblastoma by epigenetically silencing TFPI2 through EZH2 and LSD1. Aging (Albany NY) (2019) 11(11):3811. doi: 10.18632/aging. 102018

22. Wu P, Cai J, Chen Q, Han B, Meng X, Li Y, et al. Lnc-TALC promotes O 6methylguanine-DNA methyltransferase expression via regulating the c-Met pathway by competitively binding with miR-20b-3p. Nat Commun (2019) 10 (1):1-15. doi: 10.1038/s41467-019-10025-2

23. Zhang SY, Huang SH, Gao SX, Wang YB, Jin P, Lu FJ. Upregulation of lncRNA RMRP promotes the activation of cardiac fibroblasts by regulating miR-613. Mol Med Rep (2019) 20(4):3849-57. doi: 10.3892/mmr.2019.10634

24. Gao X, He H, Zhu X, Xie S, Cao Y. LncRNA SNHG20 promotes tumorigenesis and cancer stemness in glioblastoma via activating PI3K/Akt/mTOR signaling pathway. Neoplasma (2019) 2019:532-42. doi: 10.4149/neo_2018_180829N656

25. Li H, Yuan X, Yan D, Li D, Guan F, Dong Y, et al. Long non-coding RNA MALAT1 decreases the sensitivity of resistant glioblastoma cell lines to temozolomide. Cell Physiol Biochem (2017) 42(3):1192-201. doi: 10.1159/ 000478917

26. Cai T, Liu Y, Xiao J. Long noncoding RNA MALAT 1 knockdown reverses chemoresistance to temozolomide via promoting micro RNA-101 in glioblastoma. Cancer Med (2018) 7(4):1404-15. doi: 10.1002/cam4.1384
27. Chen W, Xu X-K, Li J-L, Kong K-K, Li H, Chen C, et al. MALAT1 is a prognostic factor in glioblastoma multiforme and induces chemoresistance to temozolomide through suppressing miR-203 and promoting thymidylate synthase expression. Oncotarget (2017) 8(14):22783. doi: 10.18632/ oncotarget.15199

28. Wu W, Yu T, Wu Y, Tian W, Zhang J, Wang Y. The miR155HG/miR-185/ ANXA2 loop contributes to glioblastoma growth and progression. J Exp Clin Cancer Res (2019) 38(1):1-14. doi: 10.1186/s13046-019-1132-0

29. Mazor G, Levin L, Picard D, Ahmadov U, Carén H, Borkhardt A, et al. The lncRNA TP73-AS1 is linked to aggressiveness in glioblastoma and promotes temozolomide resistance in glioblastoma cancer stem cells. Cell Death Dis (2019) 10(3):1-14. doi: 10.1038/s41419-019-1477-5

30. Toraih EA, El-Wazir A, Hussein MH, Khashana MS, Matter A, Fawzy MS, et al. Expression of long intergenic non-coding RNA, regulator of reprogramming, and its prognostic value in patients with glioblastoma. Int $J$ Biol Markers (2019) 34(1):69-79. doi: 10.1177/1724600818814459

31. Chen X, Li L, Qiu X, Wu H. Long non-coding RNA HOXB-AS1 promotes proliferation, migration and invasion of glioblastoma cells via HOXB-AS1/ miR-885-3p/HOXB2 axis. Neoplasma (2019) 2019. doi: 10.4149/ neo_2018_180606N377

32. Chen $\mathrm{H}$, Zong J, Wang S. LncRNA GAPLINC promotes the growth and metastasis of glioblastoma by sponging miR-331-3p. Eur Rev Med Pharmacol Sci (2019) 23(1):262-70. doi: 10.26355/eurrev_201901_16772

33. Liao K, Ma X, Chen B, Lu X, Hu Y, Lin Y, et al. Upregulated AHIF-mediated radioresistance in glioblastoma. Biochem Biophys Res Commun (2019) 509 (2):617-23. doi: 10.1016/j.bbrc.2018.12.136

34. Dai X, Liao K, Zhuang Z, Chen B, Zhou Z, Zhou S, et al. AHIF promotes glioblastoma progression and radioresistance via exosomes. Int J Oncol (2019) 54(1):261-70. doi: 10.3892/ijo.2018.4621

35. Tian Y, Zheng Y, Dong X. AGAP2-AS1 serves as an oncogenic lncRNA and prognostic biomarker in glioblastoma multiforme. J Cell Biochem (2019) 120 (6):9056-62. doi: 10.1002/jcb.28180

36. Fawzy MS, Ellawindy A, Hussein MH, Khashana MS, Darwish MK, AbdelDaim MM, et al. Long noncoding RNA H19, and not microRNA miR-326, is over-expressed and predicts survival in glioblastoma. Biochem Cell Biol (2018) 96(6):832-9. doi: 10.1139/bcb-2018-0122

37. Wu W, Hu Q, Nie E, Yu T, Wu Y, Zhi T, et al. Hypoxia induces H19 expression through direct and indirect Hif-1 $\alpha$ activity, promoting oncogenic effects in glioblastoma. Sci Rep (2017) 7:45029. doi: 10.1038/srep45029

38. Jiang X, Yan Y, Hu M, Chen X, Wang Y, Dai Y, et al. Increased level of H19 long noncoding RNA promotes invasion, angiogenesis, and stemness of glioblastoma cells. J Neurosurg (2016) 124(1):129-36. doi: 10.3171/2014.12.JNS1426

39. Li W, Jiang P, Sun X, Xu S, Ma X, Zhan R. Suppressing H19 modulates tumorigenicity and stemness in U251 and U87MG glioma cells. Cell Mol Neurobiol (2016) 36(8):1219-27. doi: 10.1007/s10571-015-0320-5

40. Cai J, Zhang J, Wu P, Yang W, Ye Q, Chen Q, et al. Blocking LINC00152 suppresses glioblastoma malignancy by impairing mesenchymal phenotype

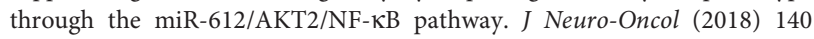
(2):225-36. doi: 10.1007/s11060-018-2951-0

41. Reon BJ, Karia BTR, Kiran M, Dutta A. LINC00152 promotes invasion through a $3^{\prime}$-hairpin structure and associates with prognosis in glioblastoma. Mol Cancer Res (2018) 16(10):1470-82. doi: 10.1158/15417786.MCR-18-0322

42. Liu X, Zhao H, Luo Y, Ma X, Xu M. LncRNA LINC00152 promoted glioblastoma progression through targeting the miR-107 expression. Environ Sci Pollut Res (2018) 25(18):17674-81. doi: 10.1007/s11356-0181784-x

43. Liu C, Fu H, Liu X, Lei Q, Zhang Y, She X, et al. LINC00470 Coordinates the Epigenetic Regulation of ELFN2 to Distract GBM Cell Autophagy. Mol Ther (2018) 26(9):2267-81. doi: 10.1016/j.ymthe.2018.06.019

44. Liu C, Zhang Y, She X, Fan L, Li P, Feng J, et al. A cytoplasmic long noncoding RNA LINC00470 as a new AKT activator to mediate glioblastoma cell autophagy. J Hematol Oncol (2018) 11(1):77. doi: 10.1186/s13045-018-0619-z

45. Zhang L, Wang Q, Wang F, Zhang X, Tang Y, Wang S. LncRNA LINC01446 promotes glioblastoma progression by modulating miR-489-3p/TPT1 axis. Biochem Biophys Res Commun (2018) 503(3):1484-90. doi: 10.1016/ j.bbrc.2018.07.067 
46. Zhou Y, Dai W, Wang H, Pan H, Wang Q. Long non-coding RNA CASP5 promotes the malignant phenotypes of human glioblastoma multiforme. Biochem Biophys Res Commun (2018) 500(4):966-72. doi: 10.1016/ j.bbrc.2018.04.217

47. Wang H, Li L, Yin L. Silencing LncRNA LOXL1-AS1 attenuates mesenchymal characteristics of glioblastoma via NF- $\mathrm{BB}$ pathway. Biochem Biophys Res Commun (2018) 500(2):518-24. doi: 10.1016/j.bbrc.2018.04.133

48. Gao Y, Xu Y, Wang J, Yang X, Wen L, Feng J. LncRNA MNX1-AS1 promotes glioblastoma progression through inhibition of miR-4443. Oncol Res Featuring Preclinical Clin Cancer Ther (2019) 27(3):341-7. doi: 10.3727/ 096504018X15228909735079

49. Tan SK, Pastori C, Penas C, Komotar RJ, Ivan ME, Wahlestedt C, et al. Serum long noncoding RNA HOTAIR as a novel diagnostic and prognostic biomarker in glioblastoma multiforme. Mol Cancer (2018) 17(1):74. doi: 10.1186/s12943-018-0822-0

50. Zhou X, Ren Y, Zhang J, Zhang C, Zhang K, Han L, et al. HOTAIR is a therapeutic target in glioblastoma. Oncotarget (2015) 6(10):8353. doi: 10.18632/oncotarget.3229

51. Zhang K, Sun X, Zhou X, Han L, Chen L, Shi Z, et al. Long non-coding RNA HOTAIR promotes glioblastoma cell cycle progression in an EZH2 dependent manner. Oncotarget (2015) 6(1):537. doi: 10.18632/oncotarget.2681

52. Ren J, Yang Y, Xue J, Xi Z, Hu L, Pan S-J, et al. Long noncoding RNA SNHG7 promotes the progression and growth of glioblastoma via inhibition of miR5095. Biochem Biophys Res Commun (2018) 496(2):712-8. doi: 10.1016/ j.bbrc.2018.01.109

53. Chen Q, Cai J, Wang Q, Wang Y, Liu M, Yang J, et al. Long noncoding RNA NEAT1, regulated by the EGFR pathway, contributes to glioblastoma progression through the WNT/ $\beta$-catenin pathway by scaffolding EZH2. Clin Cancer Res (2018) 24(3):684-95. doi: 10.1158/1078-0432.CCR-17-0605

54. Gong W, Zheng J, Liu X, Ma J, Liu Y, Xue Y. Knockdown of NEAT1 restrained the malignant progression of glioma stem cells by activating microRNA let-7e. Oncotarget (2016) 7(38):62208. doi: 10.18632/oncotarget.11403

55. Su R, Cao S, Ma J, Liu Y, Liu X, Zheng J, et al. Knockdown of SOX2OT inhibits the malignant biological behaviors of glioblastoma stem cells via up-regulating the expression of miR-194-5p and miR-122. Mol Cancer (2017) 16(1):1-22. doi: 10.1186/s12943-017-0737-1

56. Cai H, Liu X, Zheng J, Xue Y, Ma J, Li Z, et al. Long non-coding RNA taurine upregulated 1 enhances tumor-induced angiogenesis through inhibiting microRNA-299 in human glioblastoma. Oncogene (2017) 36(3):318-31. doi: 10.1038/onc.2016.212

57. Mineo M, Ricklefs F, Rooj AK, Lyons SM, Ivanov P, Ansari KI, et al. The long non-coding RNA HIF1A-AS2 facilitates the maintenance of mesenchymal glioblastoma stem-like cells in hypoxic niches. Cell Rep (2016) 15(11):2500-9. doi: 10.1016/j.celrep.2016.05.018

58. Yao Y, Ma J, Xue Y, Wang P, Li Z, Liu J, et al. Knockdown of long non-coding RNA XIST exerts tumor-suppressive functions in human glioblastoma stem cells by up-regulating miR-152. Cancer Lett (2015) 359(1):75-86. doi: 10.1016/j.canlet.2014.12.051

59. Cao Y, Wang P, Ning S, Xiao W, Xiao B, Li X. Identification of prognostic biomarkers in glioblastoma using a long non-coding RNA-mediated, competitive endogenous RNA network. Oncotarget (2016) 7(27):41737. doi: 10.18632 /oncotarget.9569

60. Tang G, Luo L, Zhang J, Zhai D, Huang D, Yin J, et al. IncRNA LINC01057 promotes mesenchymal differentiation by activating NF- $\mathrm{KB}$ signaling in glioblastoma. Cancer Lett (2020) 498:152-64. doi: 10.1016/ j.canlet.2020.10.047

61. Toraih EA, Alghamdi SA, El-Wazir A, Hosny MM, Hussein MH, Khashana MS, et al. Dual biomarkers long non-coding RNA GAS5 and microRNA-34a co-expression signature in common solid tumors. PLoS One (2018) 13(10): e0198231. doi: 10.1371/journal.pone.0198231

62. Ren S, Xu Y. AC016405. 3, a novel long noncoding RNA, acts as a tumor suppressor through modulation of TET2 by microRNA-19a-5p sponging in glioblastoma. Cancer Sci (2019) 110(5):1621. doi: 10.1111/cas.14002

63. Chu L, Yu L, Liu J, Song S, Yang H, Han F, et al. Long intergenic non-coding LINC00657 regulates tumorigenesis of glioblastoma by acting as a molecular sponge of miR-190a-3p. Aging (Albany NY) (2019) 11(5):1456. doi: 10.18632/ aging. 101845
64. Xu N, Liu B, Lian C, Doycheva DM, Fu Z, Liu Y, et al. Long noncoding RNA AC003092. 1 promotes temozolomide chemosensitivity through miR-195/ TFPI-2 signaling modulation in glioblastoma. Cell Death Dis (2018) 9(12):116. doi: 10.1038/s41419-018-1183-8

65. Zhang L, Cao Y, Wei M, Jiang X, Jia D. Long noncoding RNA-RNCR3 overexpression deleteriously affects the growth of glioblastoma cells through miR-185-5p/Krüppel-like factor 16 axis. J Cell Biochem (2018) 119 (11):9081-9.

66. Liu J, Wang W, Zhang X, Du Q, Li H, Zhang Y. Effect of downregulated IncRNA NBAT1 on the biological behavior of glioblastoma cells. Eur Rev Med Pharmacol Sci (2018) 22(9):2715-22. doi: 10.26355/eurrev_201805_14968

67. Shang C, Tang W, Pan C, Hu X, Hong Y. Long non-coding RNA TUSC7 inhibits temozolomide resistance by targeting miR-10a in glioblastoma. Cancer Chemother Pharmacol (2018) 81(4):671-8. doi: 10.1007/s00280-0183522-y

68. Liu S, Mitra R, Zhao M-M, Fan W, Eischen CM, Yin F, et al. The potential roles of long noncoding RNAs (lncRNA) in glioblastoma development. Mol Cancer Ther (2016) 15(12):2977-86. doi: 10.1158/1535-7163.MCT-16-0320

69. Liu Y, Xu N, Liu B, Huang Y, Zeng H, Yang Z, et al. Long noncoding RNA RP11-838N2. 4 enhances the cytotoxic effects of temozolomide by inhibiting the functions of miR-10a in glioblastoma cell lines. Oncotarget (2016) 7 (28):43835. doi: 10.18632/oncotarget.9699

70. Shen J, Hodges TR, Song R, Gong Y, Calin GA, Heimberger AB, et al. Serum HOTAIR and GAS5 levels as predictors of survival in patients with glioblastoma. Mol Carcinog (2018) 57(1):137-41. doi: 10.1002/mc.22739

71. Wang R, Zhang S, Chen X, Li N, Li J, Jia R, et al. CircNT5E acts as a sponge of miR-422a to promote glioblastoma tumorigenesis. Cancer Res (2018) 78 (17):4812-25. doi: 10.1158/0008-5472.CAN-18-0532

72. Li X, Diao H. Circular RNA circ_0001946 acts as a competing endogenous RNA to inhibit glioblastoma progression by modulating miR-671-5p and CDR1. J Cell Physiol (2019) 234(8):13807-19. doi: 10.1002/jcp.28061

73. Qi X, Yu XJ, Wang XM, Song TN, Zhang J, Guo XZ, et al. Knockdown of KCNQ1OT1 Suppresses Cell Invasion and Sensitizes Osteosarcoma Cells to CDDP by Upregulating DNMT1-Mediated Kcnq1 Expression. Mol Ther Nucleic Acids (2019) 17:804-18. doi: 10.1016/j.omtn.2019.06.010

74. Zhang X, Zhong B, Zhang W, Wu J, Wang Y. Circular RNA CircMTO1 inhibits proliferation of Glioblastoma cells via miR-92/WWOX signaling pathway. Med Sci Monit: Int Med J Exp Clin Res (2019) 25:6454. doi: 10.12659/MSM.918676

75. Lv X, Wang M, Qiang J, Guo S. Circular RNA circ-PITX1 promotes the progression of glioblastoma by acting as a competing endogenous RNA to regulate miR-379-5p/MAP3K2 axis. Eur J Pharmacol (2019) 863:172643. doi: 10.1016/j.ejphar.2019.172643

76. Lei B, Huang Y, Zhou Z, Zhao Y, Thapa AJ, Li W, et al. Circular RNA hsa_circ_0076248 promotes oncogenesis of glioma by sponging miR-181a to modulate SIRT1 expression. J Cell Biochem (2019) 120(4):6698-708. doi: $10.1002 / \mathrm{jcb} .27966$

77. Wang R, Zhang S, Chen X, Li N, Li J, Jia R, et al. EIF4A3-induced circular RNA MMP9 (circMMP9) acts as a sponge of miR-124 and promotes glioblastoma multiforme cell tumorigenesis. Mol Cancer (2018) 17(1):1-12. doi: 10.1186/s12943-018-0911-0

78. Qian L, Guan J, Wu Y, Wang Q. Upregulated circular RNA circ_0074027 promotes glioblastoma cell growth and invasion by regulating miR-518a-5p/ IL17RD signaling pathway. Biochem Biophys Res Commun (2019) 510(4):5159. doi: 10.1016/j.bbrc.2019.01.140

Conflict of Interest: The authors declare that the research was conducted in the absence of any commercial or financial relationships that could be construed as a potential conflict of interest.

Copyright (c) 2021 Rezaei, Tamizkar, Sharif, Taheri and Ghafouri-Fard. This is an open-access article distributed under the terms of the Creative Commons Attribution License (CC BY). The use, distribution or reproduction in other forums is permitted, provided the original author(s) and the copyright owner(s) are credited and that the original publication in this journal is cited, in accordance with accepted academic practice. No use, distribution or reproduction is permitted which does not comply with these terms. 